\title{
Calentamiento por Fotoactivación de NanoTubos de Carbono de pared simple Funcionalizados con Ácido Fólico (NTC-AF)
}

\author{
Fernando Martínez O. \\ Profesor Titular, Centro de Investigaciones en Catálisis, Cicat, \\ Escuela de Química Universidad Industrial de Santander, Bucaramanga, Colombia
}

\begin{abstract}
Resumen
Se describe métodos para la funcionalización covalente y no covalente de nanotubos de carbono de pared simple (NTC) con ácido fólico, así como su caracterización espectroscópica. La irradiación de soluciones acuosas de NTCAF con IR genera un efecto de calentamiento dependiente de la concentración, de la potencia del haz y del tipo de interacción ácido fólico-NTC; los experimentos de control indican que el aumento de la temperatura se debe solo al NTC. Los estudios biológicos preliminares indican una internalización del bioconjugado en células THP-1 y en las infectadas con parásitos de Leishmania, observándose que el efecto térmico generado por la iluminación con IR puede disminuir la población de las células infectadas.
\end{abstract}

Palabras clave: nanotubos de carbono, ácido fólico, foto-activación, calentamiento térmico.

Photo-activation Heating of Carbon Nanotubes Functionalized with Folic Acid (NTC-AF)

\begin{abstract}
Methods for covalent and non-covalent functionalization of single-walled carbon nanotubes (CNTs) with folic acid and their spectroscopic characterization are described. The irradiation of NTC-AF aqueous solutions with IR generates a heating effect that it dependent on the concentration of solution, the beam power and the type of interaction between folic acid and NTC. The control experiments show that the increase in temperature is only due to NTC. Preliminary biological studies indicate an internalization of the bioconjugate in THP-1 and infected cells with Leishmania parasites, showing that the thermal effect generated by the IR illumination can reduce the population of infected cells.
\end{abstract}

Key words: Carbon nanotubes, folic acid, photo-activation, thermal heating.

\section{Introducción}

La síntesis controlada de materiales ha permitido la aplicación de nanomateriales bioconjugados para el desarrollo de terapias alternativas a los tratamientos tradicionales usados en medicina en su lucha contra el cáncer o en las células infectadas con parásitos (Tong R. et al, 2013). Por ejemplo, la ablación térmica se presenta cuando las células se calientan por encima de un umbral de temperatura, típicamente $55^{\circ} \mathrm{C}$ (Nikfarjam M. et al, 2005). Lo cual induce a una necrosis coagulativa, una forma de muerte celular que implica la desnaturalización de las proteínas y la lisis de la membrana (Hildebrandt B. et al, 2002). Este efecto térmico localizado se puede generar por la interacción de las nanopartículas con la radiación IR o de radiofrecuencia (Gannon et al., 2007; Manthe R. et al, 2010).

Se ha demostrado que cuando los nanotubos de carbono (NTC) son expuestos a luz del infrarrojo cercano (NIR) en el rango de 700 a $1100 \mathrm{~nm}$, la cual es biológicamente transparente, pueden inducir la destrucción térmica de las células cancerosas tanto in vitro como in vivo. (Levi-Polyachenko N., et al, 2009; Fisher J. et al, 2010; Burlaka A. et al, 2010; Moon H., et al, 2009). Los NTC tienen la ventaja sobre otros nanomateriales, ya que pueden lograr la destrucción térmica de tumores, usando dosis hasta 10 veces más bajas y con una potencia de radiación hasta 3 veces menores (Robinson J. et all, 2010).

Los NTC de pared simple, presentan propiedades físicoquímicas únicas, emiten calor cuando absorben energía por radiación en el infrarrojo cercano (NIR). Los tejidos son relativamente transparentes a los rayos NIR, esto sugiere que la ablación térmica de un tumor se puede lograr con el ingreso de los NTC en las células tumorales y su exposición

\section{Correspondencia:}

Fernando Martínez O., fmartine@uis.edu.co

Recibido: 13 de marzo de 2014

Aceptado: 30 de julio de 2014 
no invasiva a la luz NIR (Chakravarty P. et al, 2008). Los NCT liberan una apreciable cantidad de energía vibracional después de su exposición a la radiación NIR (Robinson $\mathbf{J}$. T. et al, 2010), la cual dentro de un tejido produce un calentamiento localizado, que puede ser aprovechado para producir ablación térmica. (Levi-Polyachenko N. et al, 2009).

La propiedad de los NTC para convertir la luz del infrarrojo cercano (NIR) en calor, proporciona una oportunidad para preparar una nueva generación de materiales inmunoconjugados contra el cáncer mediante una fototerapia con un alto rendimiento y eficiencia. Además, la hipertermia se ha usado clínicamente en el tratamiento de tumores, ya que puede aumentar la citotoxicidad sinérgicamente cuando se combina con la quimioterapia o la radioterapia (Kosuge $\mathbf{H}$. et al, 2012; Chou H.-T. et al, 2013). La hipertermia puede aumentar selectivamente la permeabilidad de la vasculatura tumoral en comparación con la vasculatura normal, lo que puede mejorar el ingreso de medicamentos en los tumores (Kosuge H., et al, 2012).

En consecuencia los efectos térmicos generados por NTC pueden tener ventajas terapéuticas importantes, ya que estudios fármaco-cinéticos han observado que los NTC internalizados en ratones por diferentes procedimientos no generan efectos tóxicos (Robinson J. T. et al, 2010)

El uso de nanoestructuras como nanocápsulas de oro ó NTC (Wang H. et al, 2013), en las células cancerígenas con el objeto de destruirlas mediante la ablación térmica está siendo investigado por varios grupos (Loo C. et al, 2005; Huang X. et al, 2006; Gannon et al. 2007; Y. Hashida, 2014). El uso de la radiación IR (700 - 1100-nm) para la inducción de la hipertermia es particularmente atractiva porque los tejidos vivos no absorben fuertemente en este rango y la luz NIR externa puede penetrar el tejido normal sin problemas y permitir la ablación de las células en las cuales se hallan los NTC. Un aspecto que se debe considerar en la ablación térmica selectiva de células mediada por NTC es permitir su internalización selectiva mediante "anclas" que orienten su ingreso sin que interfieran con las propiedades ópticas de los NTC. El ingreso selectivo de los NTC en las células tumorales puede lograrse mediante el anclaje de los mismos con ligandos que faciliten el reconocimiento celular tales como péptidos y anticuerpos, entre otros (Burkea A. et al, 2008; Zhao D. et al, 2011; Elhissi A. M. A. et al, 2012).

Se ha observado que la química de la superficie de los nanotubos es crítica para su comportamiento in vivo, lo cual probablemente se aplica a la mayoría de los nanomateriales con fines biológicos. El carácter hidrófobo de los NTC no permite su unión a especies biológicas. Esta hidro fobicidad tiene que bloquearse mediante una funcionalización química adecuada tal como se ha propuesto el recubrimiento de NTC con PEG convirtiéndolos en inertes biológicamente y así permitiendo su circulación prolongada en el torrente sanguíneo, baja captación y una liberación relativamente rápida de los órganos y excreción del cuerpo (Liu Z. 2008; Robinson J.T. et al, 2010; Zhou F.F. et al, 2011).

Uno de los requisitos fundamentales para lograr la aplicación biológica de los NTC es la posibilidad de modificar químicamente la superficie en un proceso conocido como funcionalización. La funcionalización de los NTC con biomoléculas (ADN, anticuerpos, proteínas, péptidos y enzimas) así como otras nanopartículas tales como oro y plata, polímeros, liposomas y nanotubos biológicos han permitido aumentar el número de aplicaciones biomédicas. Entre las más importantes se tienen: la entrega controlada de fármacos, diagnóstico y detección de enfermedades y la terapia fotodinámica (Vardharajula S. et al, 2012; Chen H. et al, 2014).

El ácido fólico (AF) es una de las biomoléculas más utilizadas en aplicaciones biomédicas, ha sido utilizada como blanco estratégico en la detección, diagnóstico y tratamiento de enfermedades como el cáncer (Bandara N. A. et al, 2014; Boca-Farcau S.et al, 2014), debido a la sobreexpresión de receptores de folato observadas en células cancerígenas y en algunos casos en la células infectadas con Leishmania (Novoa L. V., 2012; Castillo J. J. et al, 2013). Son pocos los estudios relacionados con la utilización de NTC funcionalizados con AF para permitir el ingreso selectivo de las nanoparticulas en células enfermas o infectadas con parásitos como la leishmania y menos común, estudios relacionados con la detección de células cancerígenas utilizando nanotubos biológicos funcionalizados con AF (Castillo J. J., 2012; Graham E. G. et al, 2013; Niu L. et al, 2013; Zhang Y L. X, et al, 2013).

En el presente trabajo se describen algunos procedimientos que permiten la funcionalización de los nanotubos de carbono de pared simple (NTC) con ácido fólico (AF), su caracterización y evaluación del efecto térmico al ser irradiados con radiación IR, con el fin de destruir células cancerosas o infectadas con parásitos, por ablación térmica y por ingreso selectivo de los NTC-AF.

\section{Parte experimental}

\section{Materiales}

Los NTC, NTC-COOH de pared simple (pureza $>90 \%$ (base de carbono), $\mathrm{D} \times \mathrm{L} 4-6 \mathrm{~nm} \times 0,7-1,0 \mu \mathrm{m}$ ) y el ácido fólico, $\mathrm{AF}$, (pureza $>97 \%$ ) fueron adquiridos comercialmente (Sigma, Aldrich USA) y los otros reactivos usados fueron de grado analítico.

Funcionalización de Nanotubos de Carbono con Ácido Fólico: NTC-AF

Para realizar la funcionalización de los NTC con el AF se usaron métodos de preparación covalente y no covalente a 
temperatura ambiente. En el caso de la unión no covalente del AF al nanotubo se hizo simplemente mediante la sonicación de los dos compuestos sin el uso de una molécula enlazante al NTC. Para la unión covalente NTC-AF se llevó a cabo usando como linker una carbodiimida. Adicionalmente, se usaron NTC carboxilados que activaron mediante la N,N'diciclohexilcarbodiimida, facilitando la formación de un enlace amida que posteriormente permite la formación del enlace amida con la etilendiamina y luego con el AF.

\section{Funcionalización no covalente de NTC con AF}

En este caso se requiere realizar la dispersión del NTC, para tal efecto se tomó un recipiente de vidrio de $50 \mathrm{~mL}$ para depositar $5 \mathrm{mg}$ de NTC y luego se agregó $5 \mathrm{~mL}$ de una solución ligeramente básica ( $\mathrm{pH}$ 9) de $\mathrm{AF}$, la cual se preparó previamente mezclando $6.5 \mathrm{mg}$ de AF y $10 \mathrm{~mL}$ de $\mathrm{NaOH} 1$ $\mathrm{M}$, luego se aforó a un volumen de $25 \mathrm{~mL}$ con agua destilada [Castillo J. J. et al, 2012].

La mezcla NTC-AF se agitó durante 5 minutos y luego se sonicó durante 20 minutos en una baño termostatado a $15^{\circ} \mathrm{C}$. Posteriormente la solución se centrifugó a $12000 \mathrm{rpm}$ durante $20 \mathrm{~min}$, el sobrenadante fue separado. Finalmente la solución fue dializada tres veces con agua destilada para eliminar el exceso de AF que no reaccionó. El esquema de preparación usado se indica en la siguiente figura 1.

Adicionalmente, se realizó un estudio teórico de este sistema mediante un método híbrido de cálculo (N-Integrated Orbital Molecular y Molecular Mechanics (B3LYP (6-31G (d): UFF)). Los resultados confirmaron que la interacción se produce a través de puentes de hidrógeno entre los protones del fragmento glutámico del AF y los electrones p del NTC (Rozo C. et al, 2013).

\section{Funcionalización covalente de NTC con AF}

En una primera etapa se realizó la preparación del conjugado formado entre los nanotubos de pared simple de carbono, chitosan y ácido fólico, siguiendo el procedimiento descrito por Castillo (Castillo J. J., et al, 2012).

\section{Preparación del conjugado nanotubo de carbono chitosan y ácido fólico: NTC-chitosan y NTC-AF}

En un frasco de vidrio se sonicaron $5 \mathrm{mg}$ de NTC con una solución acuosa de chitosan (pureza <75\%) $(30 \% \mathrm{p} / \mathrm{v})$ durante 1 hora. Luego, la solución fue centrifugada a 2800 rpm durante 20 minutos; el sobrenadante se recogió y se separó cuidadosamente del sólido remanente y la solución de NTC se almacenó a $4^{\circ} \mathrm{C}$, la se usa luego en la funcionalización con el AF.

La adición del AF al sistema NTC-chitosan se realizó mediante una metodología similar a la propuesta por Kam (Kang B. et al. 2009), una mezcla de solución acuosa NTC-chitosan $(5 \mathrm{~mL})$ con una solución $3.5 \mathrm{mM}$ de EDC (1-etil-3-(3-dimetilaminopropil) carbodiimida)) se agitó magnéticamente a temperatura ambiente $\left(25^{\circ} \mathrm{C}\right)$ durante 12 horas, protegiendo la mezcla de la luz. Posteriormente, a la anterior mezcla se le adicionó $500 \mu \mathrm{L}$ de una solución acuosa (2.5 mM) de AF ligeramente básica. La mezcla se dejó en agitación durante la noche y luego fue dializada tres veces
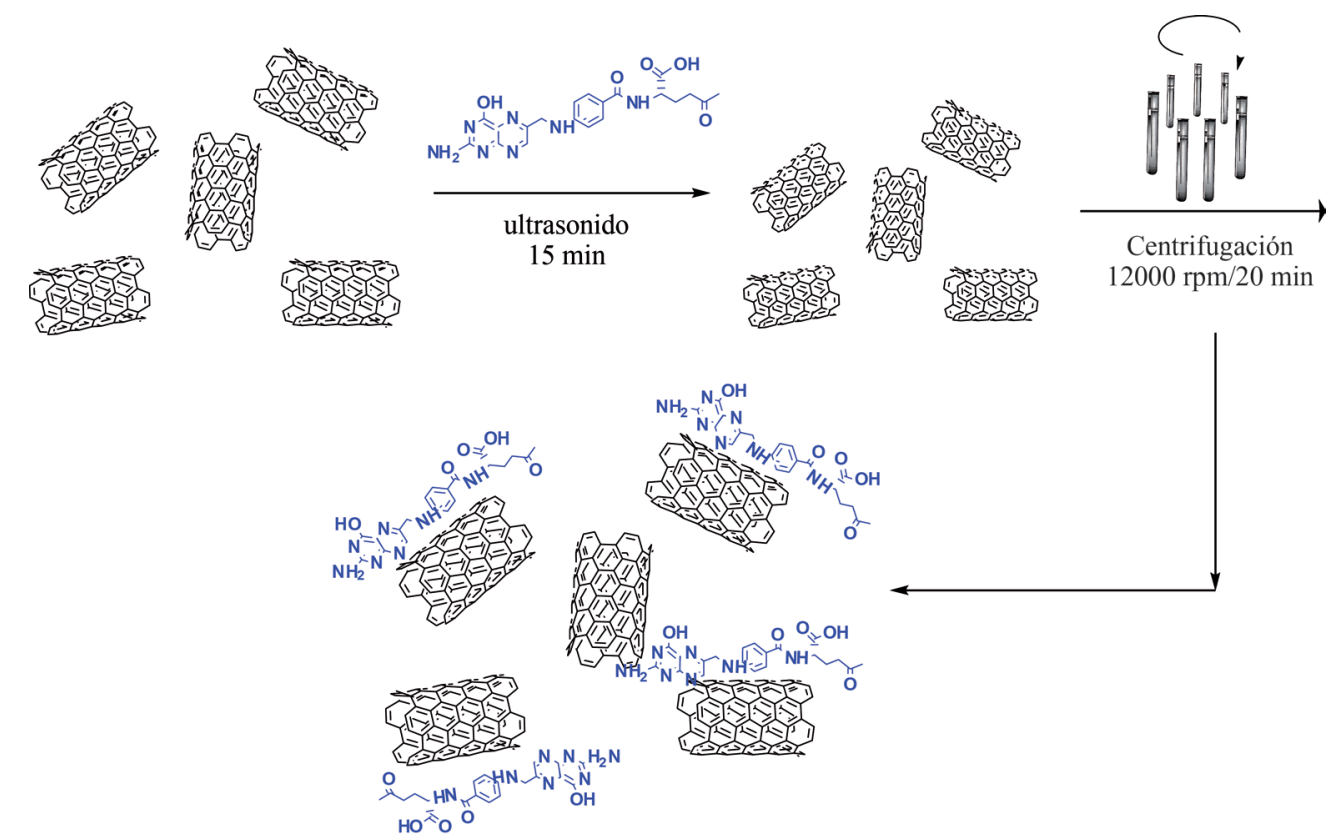

Figura 1. Esquema de la funcionalización no covalente de NTC-AF (Castillo J.J.,et al 2011). 
con una solución tampón de fosfato $(\mathrm{pH} 7.0)$ usando una membrana de diálisis (tamaño de poro 10000) para remover el exceso de AF y EDC. La estabilidad del conjugado se siguió mediante la medición del potencial zeta de la solución, la cual se almacenó a $4^{\circ} \mathrm{C}$ para su caracterización (Castillo $\mathbf{J}$. J., et al, 2012).

\section{Funcionalización covalente del nanotubo de carbono} carboxilado (NTC-COOH) con ácido fólico

$\mathrm{El}$ anclaje del AF al NTC-COOH no se realizó directamente por el grupo amino presente en el ácido AF, debido a que este grupo tiene su par electrónico comprometido en la aromaticidad de la pterina, haciéndolo menos reactivo y dificultando el ataque nucleofílico por parte de este grupo. Se decidió realizar un procedimiento usado para la aminación de la lipasa B de la Candida antartica (Galvis, M., et al. 2012), usando la $N, N^{\prime}$-diciclohexilcarbodiimida (EDAC) como agente de activación de los grupos carboxílicos presentes en la superficie de los NTC-COOH, esta permite el ataque nucleofílico de uno de los grupos amino de la EDAC, formando un enlace amida y dejando libre un grupo amino primario que actua como nucleófilo y facilita el ataque a uno de los grupos carboxilo del AF, permitiendo así la funcionalización covalente del AF al NTC (Ayala B. E. et al 2013). En la figura 2 se indica el esquema de reacción usado.

En un tubo de Falcon se mezclan 5 mg de NTC-COOH con $15 \mathrm{~mL}$ de acetonitrilo y se sonicaron durante $20 \mathrm{~min}$ a temperatura ambiente de $\left(25^{\circ} \mathrm{C}\right)$. Este procedimiento se

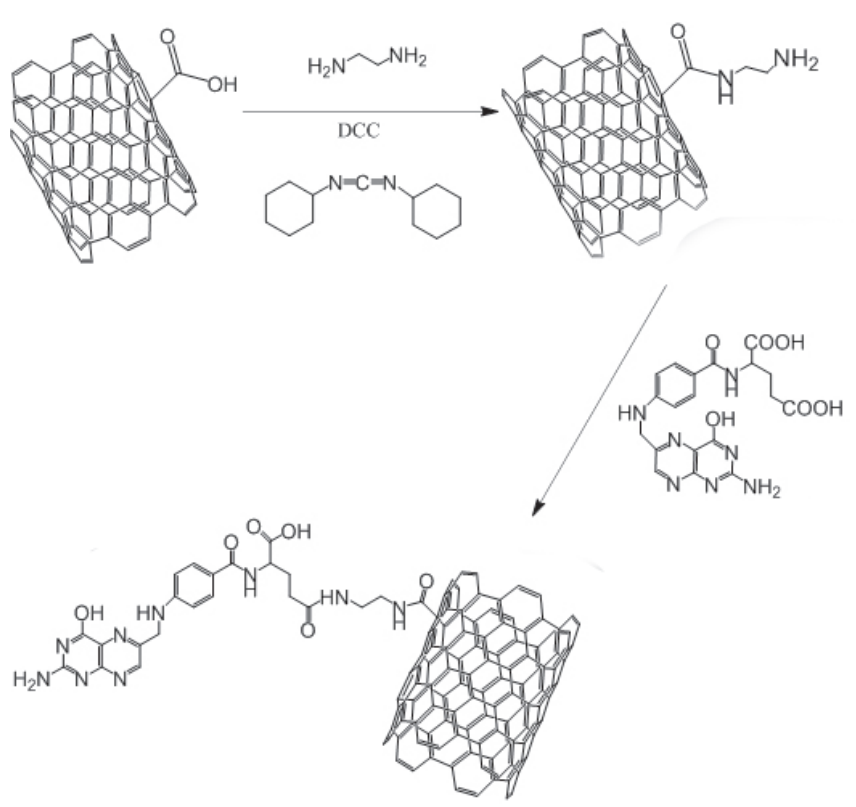

Figura 2. Esquema de la funcionalización covalente de NTC-AF (Ayala B. E. et al, 2013) repitió modificando el solvente (DMF, agua-acetonitrilo). Además para cada funcionalización obtenida (NTC-EDA (Etilendiamina) y NTC-AF) se realizó una dispersión en cada uno de los solventes mencionados.

\section{Funcionalización covalente de NTC-COOH con Etil- endiamina (NTC-EDA).}

En un vaso de vidrio se mezclaron $20 \mathrm{mg}$ de NTC-COOH y una solución acuosa de EDA. La Solución de EDA se preparó previamente, tomando $1.3 \mathrm{~mL}$ de EDA (1M) y aforando a 20 $\mathrm{mL}$ (pH 4.75) y $2 \mathrm{mg}$ de EDAC (10mM), en un baño de hielo con agitación magnética constante durante 1 hora. Luego, se centrifugó la mezcla a $14000 \mathrm{rpm}$, extrayendo el sobrenadante, lavando con agua destilada para eliminar el exceso de EDA que no reaccionó y finalmente el sólido obtenido se secó a temperatura ambiente $\left(25^{\circ} \mathrm{C}\right)$ (Ayala B. E. et al, 2013).

Funcionalización covalente de NTC-EDA con Ácido Fólico.

En un vaso de vidrio se preparó una solución de AF (10 $\mathrm{mg}$ ) en $22 \mathrm{~mL}$ de una solución tampón de fosfato $(25 \mathrm{mM}$; $\mathrm{pH}$ 4.75). Luego se adicionó $42 \mathrm{mg}$ de EDAC y $10 \mathrm{mg}$ de NTC-EDA, con agitación magnética constante durante 1 hora a temperatura ambiente. Posteriormente la mezcla se centrifugó a $14000 \mathrm{rpm}$, extrayendo el sobrenadante y lavando con agua destilada para eliminar el exceso de AF que no reaccionó. El sólido obtenido se secó a temperatura ambiente $\left(25^{\circ} \mathrm{C}\right)$ (Ayala B. E. et al, 2013).

\section{Resultados y discusión}

\section{Caracterización}

\section{Análisis del NTC-AF (no covalente)}

\section{Espectroscopia de $\mathrm{UV}$-Vis}

La funcionalización no covalente de los NTC con el AF se evidenció mediante el espectro UV-Vis, en el cual se observan tres bandas de absorción que corresponden respectivamente a la banda de absorción de la estructura tubular de los NTC $(265 \mathrm{~nm}) \mathrm{y}$ dos bandas adicionales asociadas al AF, $282 \mathrm{y}$ $364 \mathrm{~nm}$, ver figura 3 .

\section{Espectroscopia de Fluorescencia}

La asociación AF-NTC se analizó por medio del espectro de fluorescencia al excitar la solución con una longitud de onda de $364 \mathrm{~nm}$, en el espectro de emisión se observó una disminución de la emisión de fluorescencia del AF en alrededor de $475 \mathrm{~nm}$, en la cual la intensidad de la fluorescencia del AF libre y su conjugado con los NTC es muy diferente, ver figura 4. Este efecto de apagamiento de una molécula en presencia de los NTC se atribuye a mecanismos de transferencia electrónica (Cho E. S. et al, 2008).

El efecto de apagamiento del AF por los NTC puede ser un indicio de la interacción AF-NTC para formar el respectivo conjugado. 




Figura 3. Espectro UV-Vis NTC-AF, el espectro se tomó después de lavar y centrifugar el conjugado con agua destilada, para eliminar el exceso de AF.

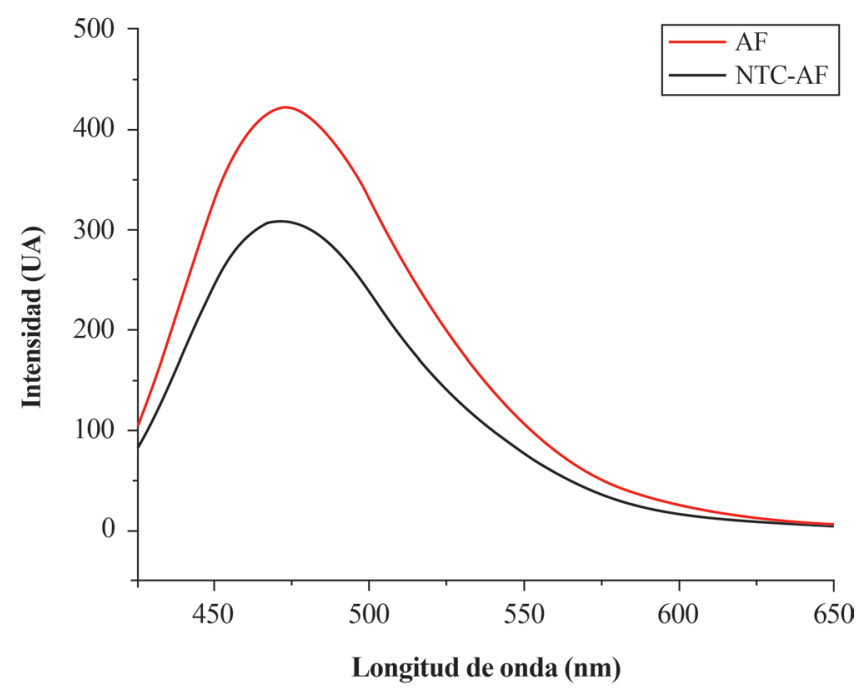

Figura 4. Espectros de emisión de AF libre y conjugado a los NTC $\left(\lambda_{\mathrm{exc}}=364 \mathrm{~nm}\right)$.

\section{Espectroscopia Raman}

El espectro Raman del NTC permite ver la modificación de los modos vibracionales por efecto de la funcionalización del NTC (Koh B., et al, 2011). Se identifica que la zona comprendida entre 200 y $300 \mathrm{~cm}^{-1}$ se presenta los modos de respiración radial conocidos como RBM (Radial Modes Breathing, siglas en ingles), los cuales presentan una relación inversa con el diámetro del nanotubo y son útiles para evidenciar la funcionalización de los NTC. Además, la presencia de una banda intensa en $1589 \mathrm{~cm}^{-1}$, conocida como la banda $\mathrm{G}$, esta asociada a las vibraciones tangenciales de los NTC. Las otras dos bandas características son las bandas $\mathrm{D}$ (desorden inducido) y G- ubicadas a $1300 \mathrm{~cm}^{-1}$ y $2600 \mathrm{~cm}^{-1}$ respectivamente, bandas asociadas a la estructura electrónica y fonónica de los NTC (Dresselhauss M., et al, 2002; Jinno M., et al, 2006).

Se ha propuesto que para evidenciar el grado de funcionalización de los NTC con alcanos lineales se analice la intensidad de la banda RBM. En nuestro caso, en el NTC funcionalizado con $\mathrm{AF}$ se observó un cambio de la intensidad de la banda a $270 \mathrm{~cm}^{-1}$. La figura 5 compara los espectros Raman del NTC y NTC-AF. Se observa una disminución en la intensidad de los NTC-AF, asociada a la presencia del AF en el NTC, la cual afecta los modos de vibración RBM, afectando principalmente vibración radial en la ("respiración" del NTC). Este fenómeno ha sido observado por otros autores y ha permitido realizar un seguimiento de la funcionalización de NTC (Kim U., et al, 2005).

Las bandas G y D, además se han usado para la caracterización de la funcionalización del NTC con AF, mediante la relación de intensidades de las bandas G y D. Cuando el valor de la relación de intensidades se aproxima a 1 , significa que un gran número de defectos superficiales están en la superficie del nanotubo. La figura 6 , se indica las bandas de los espectros Raman de los NTC $\left(\mathrm{I}_{\mathrm{D}}=2219 / \mathrm{I}_{\mathrm{G}}=11900\right)$ y NTC-AF $\left(\mathrm{I}_{\mathrm{D}}=2220 / \mathrm{I}_{\mathrm{G}}=10121\right)$, para estimar la relación de intensidades.

La leve diferencia de las relaciones de las intensidades observadas para NTC y NTC-AF, indica una interacción débil, asociada a la interacción no covalente entre el AF y el NTC. En el trabajo desarrollado por Castillo (Castillo J. J.,

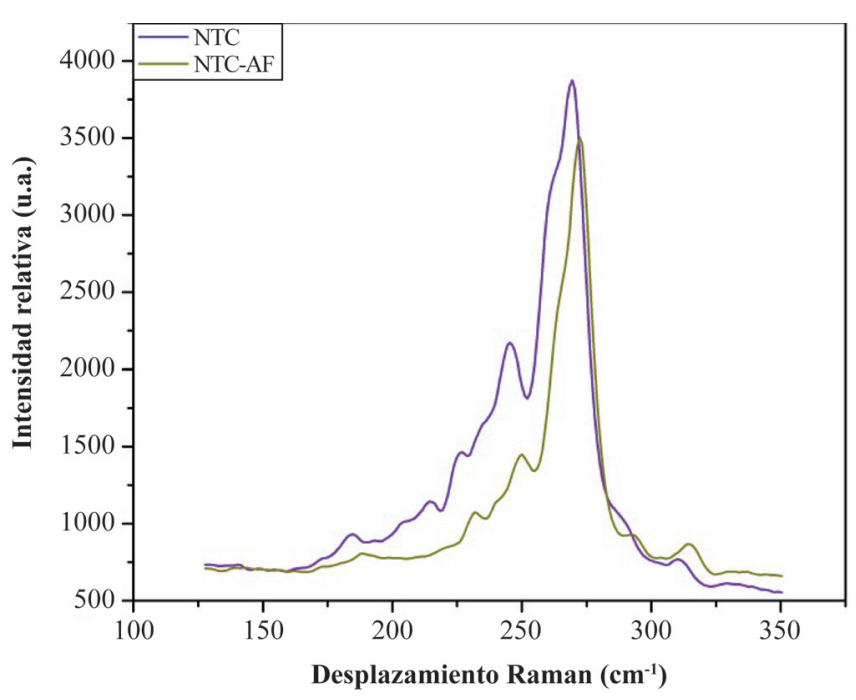

Figura 5. Comparación de los modos de vibración RBM del NTC y NTC-AF (no covalente). 




Figura 6. Espectros Raman de NTC y NTC-AF (no covalente).

2013) se ha realizado un estudio más detallado del sistema NTC-AF, incluyendo su excitación mediante dos láser (532 y $785 \mathrm{~nm}$ ), observando que la excitación con el laser de 785 nm presentó una mejor resolución de sus picos.

\section{Análisis del conjugado NTC-chitosan-AF}

\section{Espectroscopia $U \boldsymbol{V}$-vis}

El análisis por espectroscopia UV/Vis, indicó que los NTC se solubilizan en la solución acuosa de chitosan. En el espectro aparece una banda de absorción a $265 \mathrm{~nm}$, característica de los fonones resonantes y de las transiciones electrónicas de los electrones p presentes en la estructura del NTC, ver figura 7, banda que ha sido observada por otros trabajos (Attal S., et al, 2006).

El espectro UV-vis no muestra ninguna señal relacionada con el chitosan. Adicionalmente, en la región de 500-800 nm, se aprecian varios picos asociados a las singularidades de van Hove pertenecientes a $(750 \mathrm{~nm}) E_{11}$ de los NTC (Attal S. et al, 2006), indicio asociado a su dispersión.

\section{Espectroscopia de Fluorescencia}

En el espectro de fluorescencia del bioconjugado, se observó un apagamiento de la fluorescencia del chitosan dado a su interacción con el NTC. La banda de $418 \mathrm{~nm}$ en el espectro de emisión del chitosan desaparece casi en su totalidad del sistema NTC-chitosan. Esto nos induce a indicar que ocurre una interacción molecular entre el chitosan y el NTC, la cual genera el efecto de apagamiento del chitosan (Ahmad A., et al. 2009), ver figura 8.

\section{Espectroscopia Raman}

El espectro Raman permite observar evidencias acerca de la interación del chitosan al NTC. En la figura 9 se indican los espectros del NTC antes y después de su funcionalización con el chitosan. La presencia de algunas de las vibraciones características del NTC antes y después de su interacción con el chitosan (Castillo J. J., 2013), están en concordancia con los resultados de la literatura (Dresselhauss M. et al., 2002).

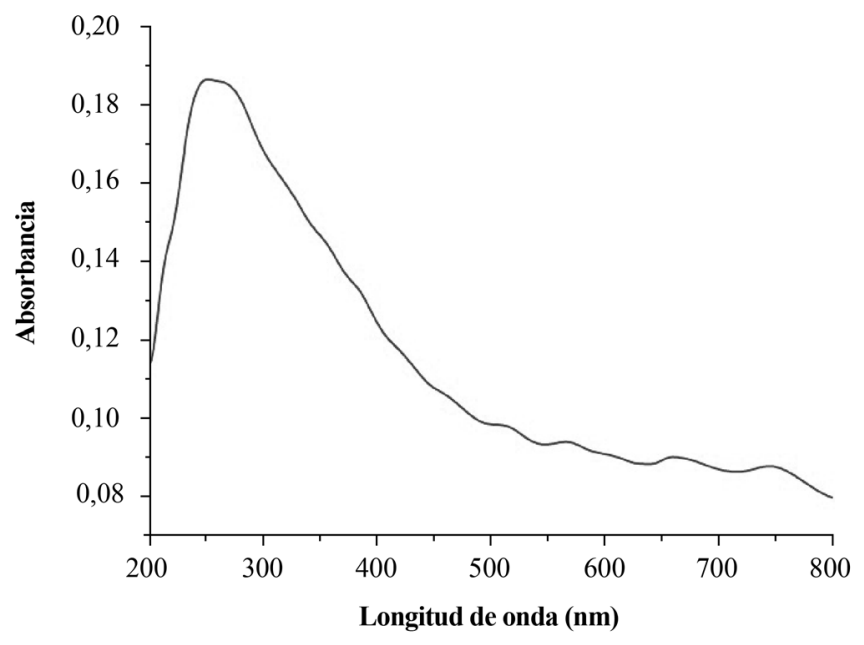

Figura 7. Espectro UV-vis de NTC-chitosan.

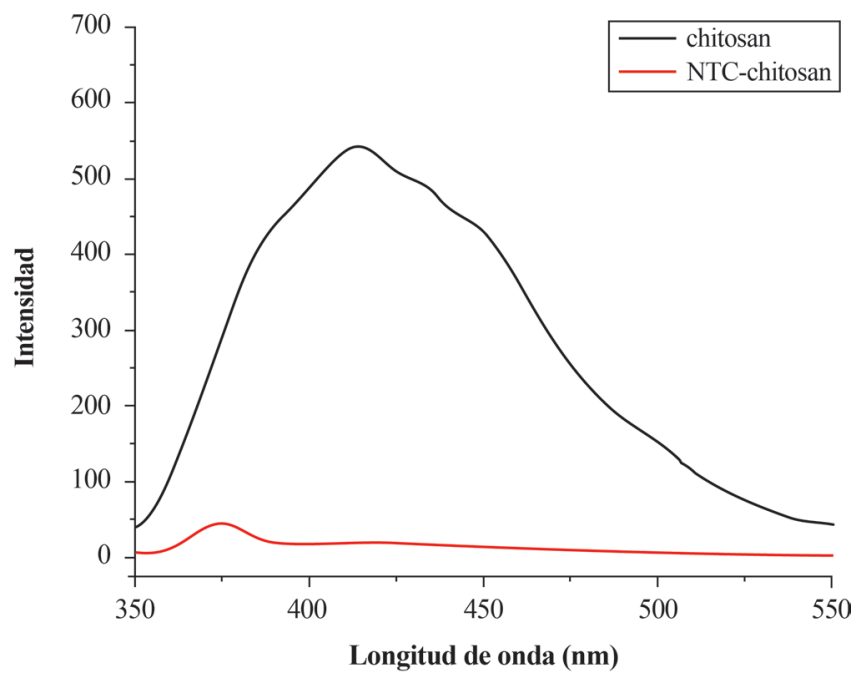

Figura 8. Espectro de emisión del chitosan y del chitosan conjugado a NTC. 


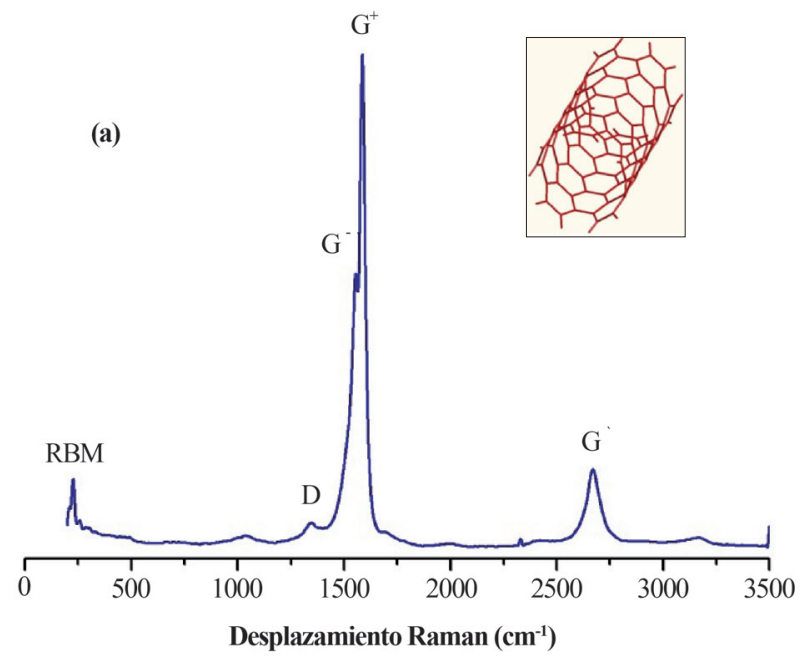

Figura 9. Espectro Raman de (a) nanotubos de carbono y (b) nanotubos de carbono-chitosan (Castillo, John, 2013).
Se aprecia una modificación de las bandas $\mathrm{G} \mathrm{y} \mathrm{G}^{\prime}$ (asociadas a la hibridación $\mathrm{sp}^{2}$ del doble enlace) que corresponden a la vibración fundamental (primer orden) de elongación tangencial y un sobretono de segundo orden ubicados a 1500 y $1650 \mathrm{~cm}^{-1}$ respectivamente. Igualmente, se observa la banda $\mathrm{D}$ en ambos espectros, ubicada entre 1250 y 1400 $\mathrm{cm}^{-1}$, banda conocida de desorden inducido y se asocia a la presencia de defectos en el NTC por interacción, que en este caso es extremadamente débil.

Se estimó adicionalmente un cambio en la relación de intensidades de la banda D y G de 0.0637 a 0.096 para el NTC sin y con chitosan respectivamente, evidenciando una interacción del chitosan con el NTC. (Castillo et al., 2012).

\section{Espectroscopia Resonancia Magnética Nuclear}

Para evidenciar la funcionalización de los NTC con el AF mediante la preparación del conjugado NTC-chitosan-AF, se realizó un análisis de RMN bidimensional (DOSY), técnica llamada cromatografía de $R M N$, usada para separar los componentes de una mezcla compleja (Marega R et al., 2010). El espectro se midió disolviendo $400 \mu \mathrm{L}$ de la muestra en $100 \mu \mathrm{L}$ de agua deuterada $\left(\mathrm{D}_{2} \mathrm{O}\right)$ y en el experimento DOSY se utilizó un gradiente pulsado por medio de una secuencia programada (pulso ledbpgp2s, Bruker), por cada gradiente se utilizaron 32 barridos y un tiempo de difusión $0.05 \mathrm{~s}$. Todos los experimentos fueron realizados a $298 \mathrm{~K}$. Los espectros se midieron en un espectrómetro de $400 \mathrm{MHz}$ (Bruker Avance III) y se analizaron con el software Topspin 2.1.

Los respectivos espectros ${ }^{1} \mathrm{H}-\mathrm{RMN}$ de la carbodiimida, $\mathrm{AF}$ libre, chitosan y conjugado NTC-chitosn-AF se indican en la figura 10. Se evidencia en los espectros las señales correspondientes del chitosan, AF y el conjugado.

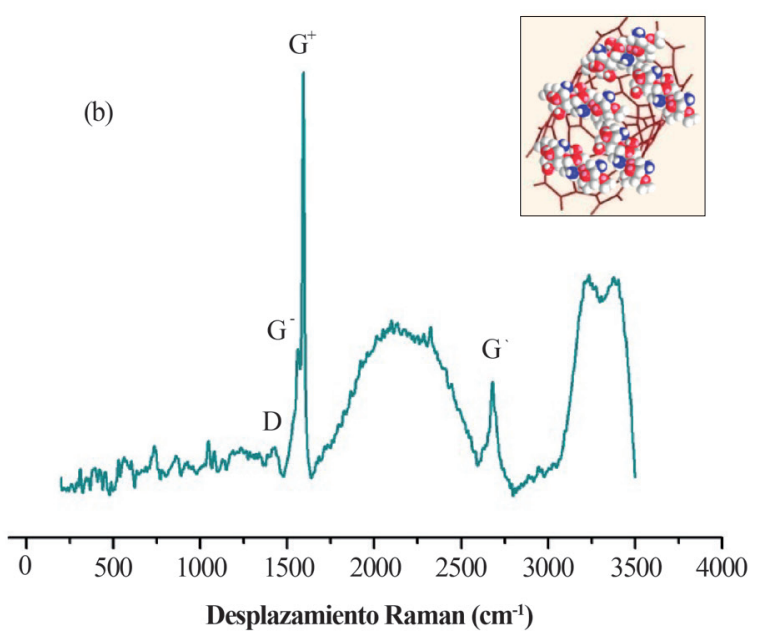

En el espectro la señal intensa a $1.90 \mathrm{ppm}$ se asigna a los protones metilicos de la isourea, formada como producto secundario de la reacción chitosan y AF. Las otras señales protónicas a $6.37(\mathrm{~d}, \mathrm{~J}=8.7 \mathrm{~Hz}, 2 \mathrm{H}), 7.21(\mathrm{~d}, \mathrm{~J}=1.7 \mathrm{~Hz}, 2 \mathrm{H})$ corresponden a desplazamientos químicos de los protones de la región del ácido p-amino benzoico del AF y la señal a 8.61 $(\mathrm{s}, 1 \mathrm{H})$ pertenece al protón de la parte pteridina del folato.

Adicionalmente, se observa un desplazamiento a campo alto de los protones aromáticos del AF conjugado comparado con las señales del AF libre, señales en $6.12(\mathrm{~d}, \mathrm{~J}=8.3 \mathrm{~Hz}, 2 \mathrm{H})$, $7.06(\mathrm{~d}, \mathrm{~J}=8.3 \mathrm{~Hz}, 2 \mathrm{H})$ y $7.93(\mathrm{~s}, 1 \mathrm{H})$. Este desplazamiento probablemente esta asociado al efecto protector de los electrones $\pi$ de los NTC, los cuales inducen una corriente y un campo magnético opuesta a la dirección del campo aplicado, generando un efecto protector y así desplaza las señales del AF hacia campo alto.

La determinación del coeficiente de difusión mediante un experimento de RMN-DOSY de NTC y NTC-AF, permite evidencias acerca de la interacción del AF al NTC (Marega R., 2010). A partir del espectro medido por el 2D DOSYRMN, se calcula el log natural de los coeficientes de difusión, cuyos detalles son indicados en el trabajo doctoral de John Castillo (Castillo J. J., 2013). El valor estimado de los coeficientes de difusión evidencian que la difusión del AF cambia notoriamente, observando una difusión muy rápida para el $\mathrm{AF}$ libre, asociado a su menor tamaño, que cuando el AF esta conjugado al NTC, donde por su mayor tamaño, se difunde a una menor velocidad, estos resultados evidencian la formación del sistema bioconjugado: NTC-AF. Este análisis DOSY permite sugerir que puede ser utilizado como una herramienta para la obtener información acerca de la funcionalización de nanoestructuras de diferente origen. (Cohen Y., et al., 2005). 




Figura 10. Espectros de RMN: a) carbodiimida (EDC), b) AF, c) chitosan and d) NTC-AF, (Castillo et al., 2012).

\section{Análisis del NTC-AF (covalente)}

\section{Espectroscopia UV-VIS}

El análisis por UV-Vis, permitió realizar un seguimiento de los intermediarios formados durante el proceso de la funcionalización covalente. En la figura 11a, se indican los espectros medidos, la etilendiamina presenta un pico de máxima absorción en $275 \mathrm{~nm}$, característica de los pares electrónicos de los átomos dadores del nitrógeno y una transición $n-\sigma^{*}$ propia de los compuestos que contienen heteroátomos. En el caso del AF se presentan dos bandas de absorción en $281 \mathrm{~nm}\left(\mathrm{n}-\pi^{*}\right)$ y $345 \mathrm{~nm}$ (efecto batocromico asociado a las transiciones $\mathrm{n}-\pi^{*} \mathrm{y} \pi-\pi *$ ).

En el caso de los espectros del NTC-COOH (negro) y las respectivas modificaciones del grupo carboxílico: NTC-EDA (rojo) y NTC-AF (azul), ver figura 11b, en estos últimos se evidencian pequeños corrimientos de las posiciones de las bandas asociadas a los precursores, debido a la presencia del grupo carbonilo en NTC, y se aprecia además, las señales muy débiles (500 - $800 \mathrm{~nm})$ asociadas al NTC.

\section{Espectroscopia de Fluorescencia}

El análisis de fluorescencia UV-Vis realizado a NTC y NTC-EDA, dispersos en agua, se observa una disminución de la intensidad de la banda en el intervalo de $360-550 \mathrm{~nm}$ cuando la EDA se asocia al NTC, este apagamiento se debe al efecto desactivante del NTC (Wadzanai, C., Tebello, N., 2010). Adicionalmente, se mantiene la banda de absorción en $310 \mathrm{~nm}$ debido a la insaturación del grupo carbonilo $(\mathrm{C}=\mathrm{O})$ y formación del grupo amida con la etilendiamina, ver figura 12 .

En el caso de la fluorescencia del sistema NTC-AF, se observa un cambio en el espectro, se da un aumento de la intensidad de la banda del AF cuando interacciona con el NTC. En este caso el AF no se encuentra unido directamente al NTC, lo cual podría explicar la ausencia del efecto de apagamiento asociada a la interacción directa con el NTC, ver figura 13.

Dado a la ausencia de un efecto de apagamiento de la fluorescencia, evidencia que el método de preparación conduce a una interacción diferente, quizás covalente, del AF con los 


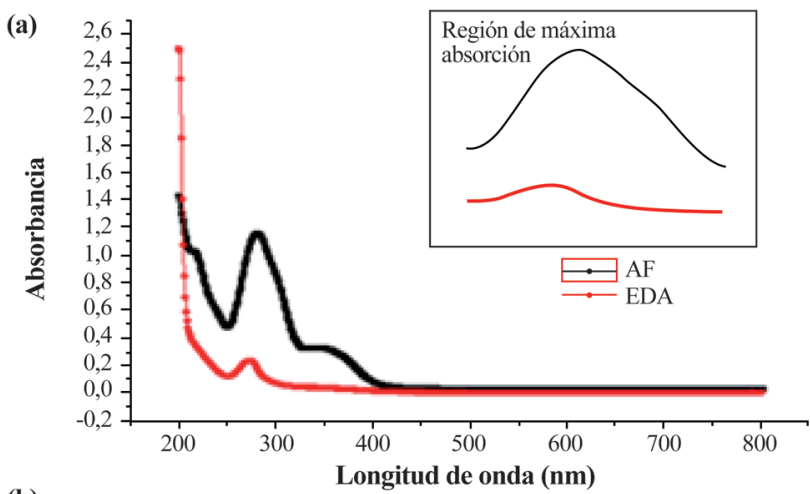

(b)

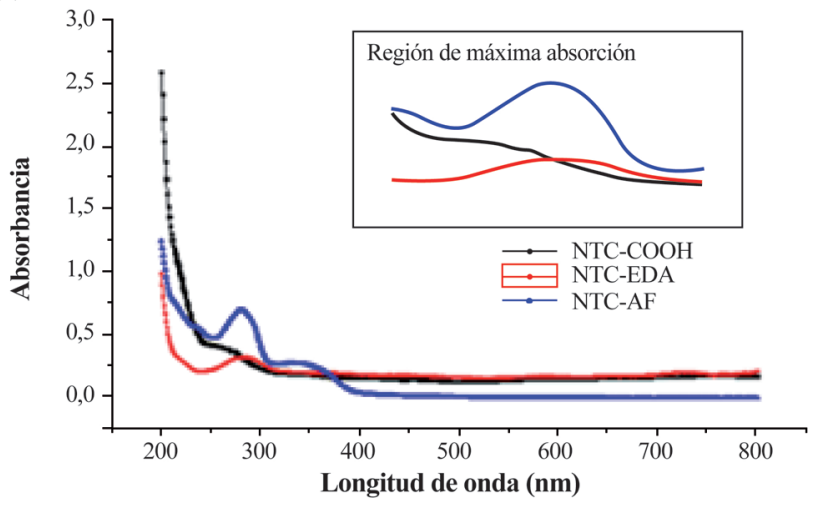

Figura 11. Espectros UV-Vis del NTC modificado. a) Precursores EDA (disuelto en agua) y AF (disuelto en acetonitrilo b) Los sistema NTC-COOH, NTC-EDA y NTC-AF, dispersos en acetonitrilo.

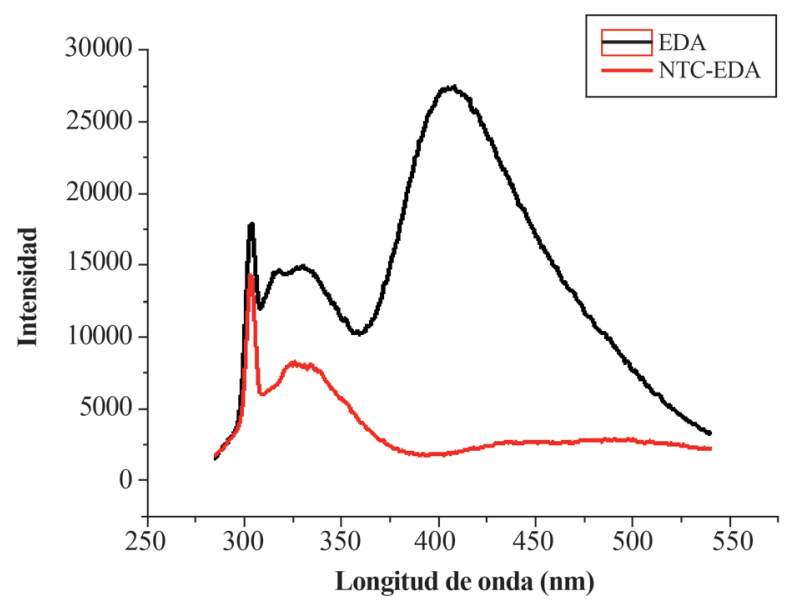

Figura 12. Espectros de Fluorescencia de la etilendiamina y el NTC-EDA dispersos en agua, para una longitud de onda de excitación de $281 \mathrm{~nm}$.

NTC, que cuando se realiza la sonicación directa entre el AF y NTC que conduce a una funcionalización no covalente y donde se observa un apagamiento de la intensidad. La literatura lo explica mediante un mecanismo de desactivación

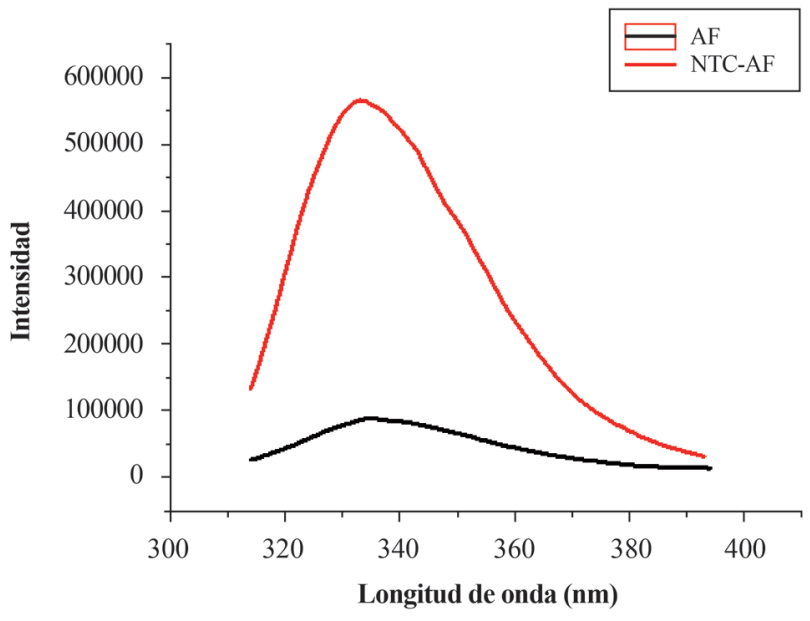

Figura 13. Espectros de Fluorescencia del AF y el NTC-AF dispersos en acetonitrilo.

de la energía colisional o transferencia Dexter, fenómeno de muy corto alcance, disminuye con la distancia de separación $\left(\mathrm{e}^{\mathrm{R}}\right)$ y depende del solapamiento entre los orbitales moleculares de las dos especies (NTC y AF).

\section{Espectroscopia Infrarroja}

Al realizar un análisis por espectroscopia IR/ATR de cada uno de los productos CNT-EDA y CNT-AF, ver figura 14, se observa la presencia de las bandas vibracionales asociadas a cada uno de los grupos funcionales (EDA y AF) de las moléculas que funcionalizan el NTC. En la tabla 1 se resumen las bandas más características de los sistemas mencionados (Ayala B. E. et al., 2013).

Al modificar los grupos superficiales $\mathrm{COOH}$ con la EDA, se observa las vibraciones correspondientes a la amida primaria (3321, 2921.17 y $\left.2846.34 \mathrm{~cm}^{-1}\right)$ que se correlacionan con las bandas I $(\mathrm{C}=\mathrm{O}, 1620.16 \mathrm{~cm}-1)$ y II $(1568.39 \mathrm{~cm}-1)$ de una amida, lo cual evidencia la modificación de los grupos carboxílicos del NTC. En el caso de la preparación del sistema NTC-AF, se observa en la región (1700-1110 $\left.\mathrm{cm}^{-1}\right)$ la presencia de las vibraciones asociadas al ácido fólico, que evidencia su interacción con el anillo. Las investigaciones realizadas acerca de la funcionalización de los NTC, resalta el hecho de aportar evidencias experimentales acerca de la funcionalización de los NTC (Nelson D. J. and Kumar R., 2013).

\section{Estudio de la distribución del tamaño de partícula}

Se puedo observar un cambio en el tamaño medio de las partículas tanto de los intermediarios como del producto final al realizar una medición del potencial $\mathrm{Z}$ de las soluciones. Se evidencia un aumento del tamaño a medida que se adicionan los grupos al NTC, resultando un mayor tamaño medio para 



Figura 14. Espectro IR de (a) NTC-COOH, (b) NTC-EDA y (c) NTC-AF.

las partículas de NTC-AF. Este crecimiento puede estar asociado al tamaño del AF, el cual es mayor con respecto al EDA ó al $\mathrm{COOH}$, como se indica en la tabla 2.

Teniendo en cuenta que la técnica supone que las partículas son esféricas, aquí se asume que el diámetro indicado para la esfera, corresponde a la longitud del NTC.
Mediante la microscopia de fuerza atómica, se evidencio una modificación del tamaño del tubo, debido a la interacción (covalente y no covalente) del AF con el NTC, observándose que las moléculas de AF envuelven la estructura del NTC, resultados que se indican en la investigación de Castillo et al.

(Castillo J. J., 2013).

Evaluación del efecto térmico del sistema NTC-AF (no covalente)

Se ha indicado que la funcionalización de los NTC con AF podría mejorar su internalización celular, facilitando el transporte de fármacos o como agente generador de calor local. Luego al irradiar las células enfermas con radiación IRC se generará un efecto térmico letal. Son pocos los estudios publicados acerca de la preparación del sistema NTC-AF. Aquí se indicarán algunos de los resultados obtenidos al irradiar el NTC-AF (covalente y no covalente).

Se prepararon soluciones acuosas de NTC-AF $(0.125-$ $0.500 \mathrm{mg} / \mathrm{mL}$ ) bajo condiciones de esterilidad, las cuales se irradiaron durante 10 minutos mediante un laser (ThorLabs, $808 \mathrm{~nm})$ controlando la temperatura y la potencia $(200,400$ y $600 \mathrm{~mW}$ ).

\section{Calentamiento de los NTC-AF en sistemas acuosos}

Se realizaron curvas de calentamiento para cada concentración y potencia, se determinó la velocidad de calentamiento en ${ }^{\circ} \mathrm{C} / \mathrm{s}$ en la solución mediante un termómetro electrónico de sonda metálica. Además, se hizo un experimento control usando únicamente agua, con una potencia de $600 \mathrm{~mW}$. Se observó que el calentamiento de la solución se debe a los NTC, ya que en el agua no se presentó aumento de la temperatura en ausencia de NTC.

En la figura 15 se indican las curvas de calentamiento medidas durante 10 min de irradiación para tres soluciones con diferente concentración de NTC-AF y modificando la potencia del diodo láser. Se determinó que 10 min era suficiente para alcanzar los valores más altos de temperatura, para tiempos superiores de irradiación se observaba una disminución de la misma

La irradiación de las soluciones de NTC-AF produce un incremento de la temperatura y se observa un incremento significativo de la misma durante los 5 primeros minutos. Adicionalmente, se observa un aumento de la temperatura al modificar la concentración de la solución así como la potencia de irradiación. Se alcanzó un valor de $43.8^{\circ} \mathrm{C}$ con una potencia de $600 \mathrm{~mW}(0.5 \mathrm{mg} / \mathrm{mL})$. Valores similares han sido indicados por Hussain. [Hussain S., et al, 2011], con valores de $44^{\circ} \mathrm{C}$ durante 4 minutos de irradiación usando un láser con una potencia de $4.5 \mathrm{~W}$. Las diferencias de temperatura se han atribuido a las condiciones usadas y al tipo de NTC empleado en ese caso (Madani S., et al., 2012). 
Tabla 1. Bandas características del espectro IR* del sistema NTC-X.

\begin{tabular}{|c|c|c|c|}
\hline \multirow[t]{2}{*}{ Tipo de vibración } & \multicolumn{3}{|c|}{ Número de onda $\left(\mathrm{cm}^{-1}\right)$} \\
\hline & NTC-COOH & NTC-EDA & NTC-AF \\
\hline Alargamiento del O-H & 3743 & 3778 y 3711 & 3543 y 3416 \\
\hline Alargamiento N-H & & 3321 & 3220 \\
\hline Alargamiento $\mathrm{C}-\mathrm{H}$ aromático & 3010 & & \\
\hline Alargamiento $\mathrm{C}-\mathrm{H}$ alifático & & 2921 y 2840 & 2923 y 2848 \\
\hline Alargamiento $\mathrm{C}=\mathrm{O}$ & 1700 & 1620 & 1689 \\
\hline Alargamiento $\mathrm{C}=\mathrm{C}$ aromático & 1541 y 1517 & 1620 y 1563 & 1612 y 1570 \\
\hline Alargamiento $\mathrm{C}=\mathrm{N}$ aromático & & & 1482 \\
\hline alargamiento asimétrico $\mathrm{COO}-$ & & & 1412 \\
\hline alargamiento simétrico & & & 1340 \\
\hline flexión en el plano C-O-H & 1426.27 & & 1481 y 1339 \\
\hline alargamiento $\mathrm{C}-\mathrm{N}$ & & 1236 y 1086 & \\
\hline Flexión fuera del plano $\mathrm{C}-\mathrm{H}$ aromaticos & 675 & 646 & 648 \\
\hline
\end{tabular}

* Los sólidos se midieron en el equipo Bruker Tensor 27, usando 32 barridos, con una resolución $2.0 \%$ de transmitancia y los espectros se analizaron con OriginLab versión 8.0.

Tabla 2. Tamaño promedio de las partículas de los sistemas funcionalizados covalentemente.

\begin{tabular}{lcl}
\hline Compuesto & Tamaño medio $(\mathbf{n m})$ & PDI* \\
\hline NTC-COOH & 120.8 & 0.318 \\
NTC-EDA & 122.0 & 0.255 \\
NTC-AF & 162.5 & 0.591 \\
\hline
\end{tabular}

*PDI: índices de polidisperción, los valores menores a 1, indica que partículas están monodispersas.

El aumento de la temperatura esta asociado a la absorción de luz por NTC que libera su energía mediante una disipación de calor que conduce al aumento local de la temperatura en la solución de NTC-AF (Burlaka A., et al, 2010).

\section{Evaluación del efecto térmico del sistema NTC-AF (covalente)}

Se realizaron ensayos para medir el efecto de la radiación infrarroja en las soluciones acuosas de NTC-AF y teniendo en cuenta los dos métodos de preparación (covalente y no covalente). Para ello se utilizó una bombilla incandescente comercial $(60 \mathrm{~W})$, la cual emite (75\% I:R, un $15 \%$ visible y el $10 \%$ UV), se evaluó el tiempo de irradiación de soluciones acuosas de NTC-AF (100 y 1000 ppm), teniendo en cuenta como blanco el agua (Ayala B. E. et al, 2013).

Se observó un aumento de la temperatura con el cambio de la concentración así como con el tiempo de irradiación, ver la figura 16. El incremento de la temperatura es mayor para aquella solución que contiene el sistema NTC-AF preparados covalentemente y es proporcional a la concentración de la solución.
Se ha indicado un aumento de la temperatura de $60^{\circ} \mathrm{C}$ al usar soluciones de NTC de pared múltiple e irradiadas con una lámpara IRC (780-1400 nm) (Hussain S. et al, 2011), resultados que están en concordancia con lo observado y permite deducir que el calentamiento de la solución es debido a la absorción de la radiación por el sistema NTC-AF.

\section{Experimentos biológicos preliminares.}

Se han realizado algunos ensayos biológicos observándose que soluciones de NTC-AF (no covalente) no presentan toxicidad en células de mamíferos THP-1 y forma dispersiones estables a pH fisiológico (Castillo et al, 2011). Además, los experimentos de internalización, THP-1 infectadas con L. panamensis y no infectadas $\left(8 \times 10^{5}\right.$ células $\left./ \mathrm{mL}\right)$ fueron cultivadas en placas de 24 pozos con laminillas circulares y tratadas con diferentes concentraciones de NTC-AF (no covalente) $(0.03-0.125 \mathrm{mg} /$ $\mathrm{mL}$ ) de 2 a 72 horas a $37^{\circ} \mathrm{C}, 5 \% \mathrm{CO}_{2}, 95 \%$ de mezcla aire, indicaron el ingreso de los NTC-AF en células THP-1 y se observó una dependencia del tiempo de internalización con la concentración de nanotubos internalizados, seguido mediante microscopia óptica por conteo directo de 300 células (Novoa V.L., 2012). Los NTC-AF se ubicaron en el citoplasma y con el aumento en el tiempo de internalización ocuparon más del $50 \%$ de la célula. Además por medio de microscopia óptica se observó la formación de aglomerados de los NTC-AF los cuales se ubicaron en especies de vacuolas. El mecanismo de ingreso de los NTC funcionalizados con AF es probablemente mediado la expresión de receptores de folato (Castillo J. J. et al, 2013).

Al realizar un experimento con células THP-1 infectadas con amastigotes intracelulares de Leishmania panamensis, se observó la internalización de los NTC-AF (no covalente) 

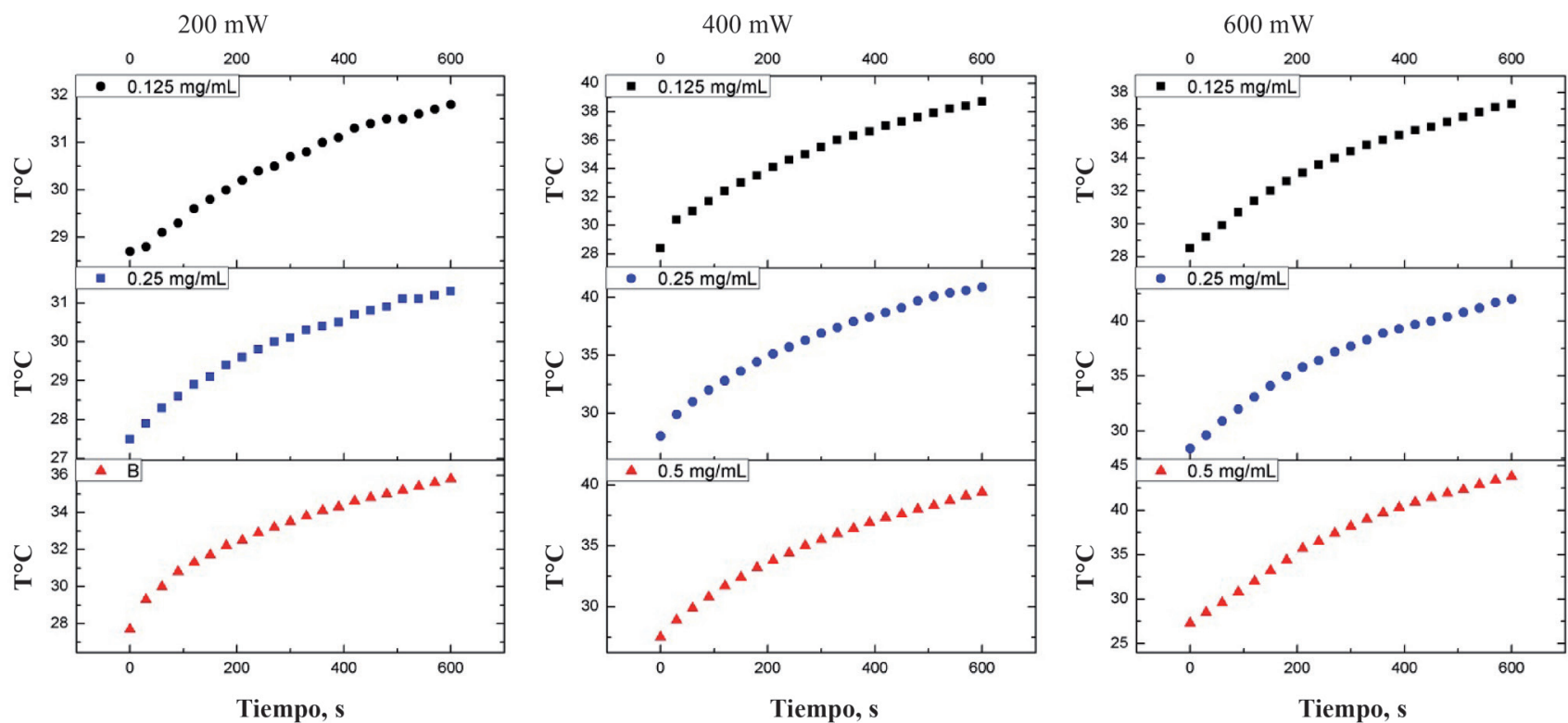

Figura 15. Curvas de calentamiento de soluciones acuosas de NTC-AF (no covalente), utilizando un diodo laser de 808 nm y modificación de la potencia (200, 400 y $600 \mathrm{~mW})$ (Castillo, John, 2013).

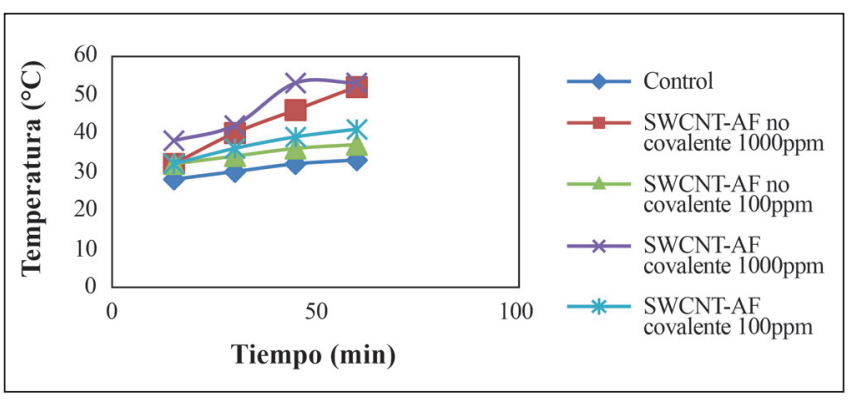

Figura 16. Efecto térmico sobre los NTC-AF funcionalizados covalente y no covalentemente (Ayala B. E. et al, 2013).

$(0.060-0.500 \mathrm{mg} / \mathrm{mL})$. Células THP-1 transformadas con PMA en cámaras de vidrio con sistema deslizante (labteck de NUNC) e infectadas con promastigotes de L. panamensis (fase estacionaria de crecimiento) utilizando una relación de infección de 1:5 célula: parásito por 48 horas a $32^{\circ} \mathrm{C}, 5 \%$ $\mathrm{CO}_{2} 95 \%$ mezcla-aire. Después fueron tratadas con diluciones seriadas 1:2 de NTC-AF (no covalente) (0.25 a $0.016 \mathrm{mg} /$ $\mathrm{mL})$ por 24 horas. Posteriormente se irradiaron con IRC $(808$ $\mathrm{nm})$ por 10 minutos. Células infectadas controles tratadas y no tratadas con NTC-AF (no covalente) fueron mantenidas sin irradiación, así como células infectadas no tratadas fueron irradiadas en las mismas condiciones. Luego, las células fueron fijadas con metanol por 10 minutos y coloreadas utilizando la tinción de Giemsa; cada experimento fue repetido tres veces. El porcentaje de infección fue determinado microscópicamente por conteo directo de 300 células infectadas. Se observó una inhibición de los amastigotes intracelulares, lo cual probablemente este asociado al efecto térmico local generado por la irradiación sobre las células infectadas (Novoa L. V., 2012). Esto nos ha orientado que en la investigación debemos estudiar los efectos asociados a la longitud de onda incidente, el tiempo de irradiación, la potencia del haz de radiación, la concentración de NTC, la naturaleza de la interacción NTC y AF (covalente y no covalente) entre otros. En consecuencia, el conjugado NTC-AF es un buen candidato para generar la ablación térmica en sistemas biológicos.

\section{Conclusiones}

Se ha indicado que los métodos usados para la funcionalización de los nanotubos de carbono de pared simple con ácido fólico, permiten una interacción covalente y no covalente entre las dos moléculas.

La caracterización espectroscópica de los sistemas NTC-AF ha permitido evidenciar la interacción entre el AF y el NTC.

La irradiación de soluciones acuosas NTC-AF con IRC (laser y lámpara) genera un efecto de calentamiento que depende de la concentración, de la potencia del haz de iluminación así como del tipo de interacción ácido fólico y NTC, ya que se observa un cambio en la temperatura de la solución. Además, los experimentos de control evidencian que los NTC son los responsables del aumento de la temperatura.

Los estudios biológicos preliminares realizados indicaron que el bioconjugado NTC-AF (no covalente) se puede internalizar en células tipo THP-1, así como aquellas células 
infectadas con la Leishmania y su mecanismo de ingreso celular probablemente esta mediado por la expresión de receptores de folato. Además, el efecto térmico generado por la iluminación con el IR puede eliminar la población de células infectadas, esto nos alienta a continuar evaluando el sistema conjugado preparado, teniendo en cuenta que se debe estudiar con más detalle factores como la longitud de onda incidente, el tiempo de irradiación, la potencia del haz de radiación, la concentración de $\mathrm{NTC}$, la naturaleza de la interacción NTC y AF entre otros.

Finalmente, la síntesis y la utilización de estos sistemas conjugados abren nuevas posibilidades para el tratamiento de enfermedades infecciosas y las células cancerosas mediante la generación de un efecto térmico localizado que permita la ablación térmica de células enfermas y el conjugado NTCAF es un buen candidato para generar la ablación térmica en sistemas biológicos.

\section{Agradecimientos}

Agradecimientos muy especiales a los Profesores Patricia Escobar y Edgar A. Páez por las amplias discusiones sobre el tema y a los investigadores que permitieron realizar los procedimientos experimentales y la continuidad de este trabajo: Doctor en Química John J. Castillo y a los Químicos Linda G. Bertel, Elizabeth Ayala B, Yeison G. Peña y la Magister en Ciencias Básicas Leidy V. Novoa L. Además, se agradece a COLCIENCIAS (Proyecto 110245921468) por la financiación del trabajo experimental.

\section{Conflicto de interés}

El autor declara que el artículo no tiene ningún conflicto de interés.

\section{Bibliografía}

Ahmad A., Kurkina T., Kern K. and Balasubramanian K., 2009. Applications of the Static Quenching of Rhodamine B by Carbon Nanotubes. Chem. Phys. Chem. 10:2251-2255.

Atthal S., Thiruvengadathan R., Regev O., 2006. Determination of the concentration of single walled carbón nanotubes in aqueous dispersión using UV-Vis absorption spectroscopy. Anal. Chem. 78 (23):8098-8104.

Ayala B, E., Peña B.Y. G., 2013. Funcionalización covalente de nanotubos de carbono de pared simple con ácido fólico y evaluación de su efecto térmico, Trabajo de grado, Director Fernando Martínez O., Escuela de Química, Facultad de Ciencias, UIS

Ayala B. E., Peña Y. G., Barbosa O., Torres R., Martínez O. F., 2013. Evaluación del efecto térmico de nanotubos de carbono de pared simple funcionalizados con ácido fólico. Rev. Invest. Univ. Quindío. 1 (24): 107-111.
Bandara N. A., Hansen M. J., and Low P. S., 2014. Effect of Receptor Occupancy on Folate Receptor Internalization. Molecular. Pharmaceutics 11 (3): 1007-1013.

Boca-Farcau S., Potara M., Simon T., Juhem A., Baldeck P., and Astilean S., 2014. Folic Acid-Conjugated, SERS-Labeled Silver Nanotriangles for Multimodal Detection and Targeted Photothermal Treatment on Human Ovarian Cancer Cells. Molecular. Pharmaceutics 11 (2): 391-399.

Burkea A., Ding X., Singh R., Kraft R. A., Levi-Polyachenko N., Rylander M. N., Szot C., Buchanan C., Whitney J., Fisher J., Hatcher H. C., D’Agostino R., Jr., Kock N. D., Ajayan P. M., Carroll D. L., Akman S., Torti F. M., and Torti S. V., 2009. Long-term survival following a single treatment of kidney tumors with multiwalled carbon nanotubes and nearinfrared radiation. PNAS 106 (31): 12897-12902.

Burlaka A., Lukin S., Prylutska S., Remeniak O., Prylutskyy Y., Shuba M., Maksimenko S., Ritter U., Scharff P., 2010. Hyperthermic effect of multi-walled carbon nanotubes stimulated with near infrared irradiation for anticancer therapy: in vitro studies. Exp. Oncol. 32 (1): 48-50.

Castillo J. J., Torres M. H., Molina D. R., Castillo-León J., Svendsen W. E., Escobar P., Martínez O. F., 2012. Monitoring the functionalization of single-walled carbon nanotubes with chitosan and folic acid by two-dimensional diffusion-ordered NMR spectroscopy. Carbon 50 (8): 26912697.

Castillo J.J., Novoa L.V., Martínez F., Escobar P., 2011. Carbon nanotubes-chitosan in HOS and THP-1 cells. Rev. Univ. Ind. Santander. Salud 43 (1): 21-6.

Castillo, J. J., Rindzevicius T., Novoa L. V., Svendsen W. E., Rozlosnik N., Boisen A., Escobar P., Martínez F. and Castillo-Léon J., 2013. Non-covalent conjugates of singlewalled carbón nanotubes and folic acid for interaction with cells over-expressing folate receptors. J. Mater. Chem. B. 1: 1475-1481.

Castillo J. J., Rozo C. E., Castillo-León J., Rindzevicius T., Svendsen W. E., Rozlosnik N., Boisen A., Martínez O. F., 2013. Computational and experimental studies of the interaction between single-walled carbon nanotubes and folic acid. Chemical Physics Letters 564: 60-64.

Castillo, John, 2013. Diseño y Preparación de Nanocompuestos Funcionalizados con Ácido Fólico y sus Aplicaciones Biomédicas, tesis doctoral en química, escuela de Química, dirigida por Patricia Escobar R. y Fernando Martínez O., UIS, enero.

Chakravarty P., Marches R., Zimmerman N. S., Swafford A. D.-E., Bajaj P., I. H. Musselman, P. Pantano, Draper R. K., and Vitetta E. S., 2008. Thermal ablation of tumor cells with antibody-functionalized single-walled carbon nanotubes. PNAS 105 (25): 8697-8702.

Cohen Y., Avram L., and Frish L., 2005. Diffusion NMR Spectroscopy in Supramolecular and Combinatorial Chemistry: An Old Parameter-New Insights, Angew. Chem. Int. Ed. 44 (4): $520-554$. 
Cho E. S., S. Hong W. and Jo W. H., 2008. A New pH Sensor Using the Fluorescence Quenching of Carbon Nanotubes. Macromol. Rapid Commun. 29 (22): 1798-1803.

Chen H., Chi X., Li B., Zhang M., Ma Y., Achilefu S. and Gu Y., 2014. Drug loaded multilayered gold nanorods for combined photothermal and chemotherapy. |Biomater. Sci., 2: 996-1006.

Chou H.-T., Wang T.-P., Lee Y., Taia N.-H., Chang H.-Y., 2013. Photothermal effects of multi-walled carbon nanotubes on the viability of BT-474 cancer cells. Materials Science and Engineering C 33 (2): 989-995.

Dresselhauss M., Dresselhaus G., Jorio A., Filho A., Pimenta A., Saito R., 2002. Single Nanotube Raman Spectroscopy. Acc. Chem. Res. 35 (12): 1070-1078.

Elhissi A. M. A., Ahmed W., Hassan I. U., Dhanak V. R., and D'Emanuele A., 2012. Carbon Nanotubes in Cancer Therapy and Drug Delivery. J. of Drug Delivery Volume 2012, Article ID 837327, doi:10.1155/2012/837327

Fisher J., Sarkar S., Buchanan C., 2010. Photothermal Response of Human and Murine Cancer Cells to Multiwalled Carbon Nanotubes after Laser Irradiation. Cancer Research, 70 (23): 9855-9864.

Galvis, M., Barbosa, O., Ruiz, M., Cruz, J., Ortiz, C., Torres R., 2012. Chemical amination of lipase B from Candida Antarctica is an efficient solution for the preparation of cross linked enzyme aggregates. Process Biochemestry 47 (12): 2373-2378

Gannon C. J., Cherukuri P., Yakobson B. I., Cognet L., Kanzius J. S., Kittrell C., Weisman R. B., Pasquali M., Schmidt H. K., Smalley R. E., Curley S. A., 2007. Carbon Nanotube-enhanced Thermal Destruction of Cancer Cells in a Noninvasive Radiofrequency Field. CANCER, Volume 110 (12): 2654-2665.

Graham E. G., MacNeill C. M., Levi-Polyachenko N. H., 2013. Quantifying folic acid-functionalized multi-walled carbon nanotubes bound to colorectal cancer cells for improved photothermal ablation. J. Nanopart. Res. 15: 1649-1662.

Hashida Y., Tanaka H, Zhou S., Kawakami S. , Yamashita F., Murakami T., Umeyama T., Imahori H., Hashida M., 2014. Photothermal ablation of tumor cells using a singlewalled carbon nanotube-peptide composite. Journal of Controlled Release 173: 59-66.

Hildebrandt B., Wust P, Ahlers O., Dieing A., Sreenivasa G, Kerner T,Felix R.,Riess H., 2002.The cellular and molecular basis of hyperthermia. Critical Reviews in Oncology/Hematology 43 (1): 33-56.

Huang X, El-Sayed IH, Qian W, El-Sayed M.A., 2006. Cancer cell imaging and photothermal therapy in the near-infrared region by using gold nanorods, J. Am. Chem. Soc. 128 (6): $2115-2120$
Hussain S., Dosser L., Payne S., Stacy B., Schrandt A., 2011. Fundamental Examination of Nanoparticle Heating Kinetics Upon Near Infrared (NIR) Irradiation. ACS Appl. Mater. Interfaces 3: 3971-3980.

Jinno M., Ando Y., Bandow S., Fan J., Yudasaka M., Ijima S., 2006. Raman scattering study for heat-treated carbon nanotubes: The origin of $\approx 1855 \mathrm{~cm}^{-1}$ Raman band. Chemical Physics Letters 418 (1-3): 109-114.

Kang B, Yu D. C, Dai Y.D., Chang S.Q., Chen D., Ding Y.T., 2009. Cancer-cell targeting and photoacoustic therapy using carbon nanotubes as "Bomb" agents. Small 5 (11): 1292 301 .

Kim U., Furtado C., Liu X., Chen G., Eklund P. 2005. Raman and IR Spectroscopy of Chemically Processed SingleWalled Carbon Nanotubes. J. Am Chem Soc. 127 (44) 15437-15445.

Koh B., Park J. B., Hou X. M. and Cheng W., 2011. Comparative Dispersion Studies of Single-Walled Carbon Nanotubes in Aqueous Solution. J. Phys. Chem. B, 115 (11): 2627-2633.

Kosuge H., Sherlock S. P., Kitagawa T., Dash R., Robinson J. T., Dai H.; McConnell M. V., 2012. Near Infrared Imaging and Photothermal Ablation of Vascular Inflammation Using Single-Walled Carbon Nanotubes. J. Am. Heart Assoc. 2012: doi: 10.1161/JAHA.112.002568

Levi-Polyachenko N., Merkel E., Jones B., Carroll D., Stewar J. H., 2009. Rapid Photothermal Intracellular Drug Delivery Using Multiwalled Carbon Nanotubes. Molecular. Pharmaceutics 6 (4): 1092-1099.

Liu Z., Davis C., Cai W., He L., Chen X., and Dai H., 2008. Circulation and long-term fate of functionalized, biocompatible single-walled carbon nanotubes in mice probed by Raman spectroscopy. PNAS 105 (5): 1410 -1415.

Loo C., Lowery A, Halas N, West J, Drezek R., 2005. Immunotargeted nanoshells for integrated cancer imaging and therapy. Nano Lett. 5 (4): $709-711$.

Madani S., Tan A., Dwek M., Seifalian A., 2012. Functionalization of single-walled carbon nanotubes and their binding to cancer cells. Int J Nanomedicine 7: 905-914.

Manthe R., Foy S., Krishnamurthy N., Sharma B., Labhasetwar V., 2010. Tumor Ablation and Nanotechnology. Molecular Pharmaceutics 7 (6): 1880-1898.

Marega R, Aroulmoji V, Bergamin M, Feruglio L, Dinon F, Bianco A., 2010. Two-Dimensional Diffusion-Ordered NMR Spectroscopy as a Tool for Monitoring Functionalized Carbon Nanotube Purification and Composition. ACS Nano. 4 (4): 2051-8.

Marega R., Aroulmoji V., Dinon F., Vaccari L., Giordani S., Bianco A., Murano E. and Prato M., 2009. Diffusion-Ordered NMR Spectroscopy in the Structural Characterization of Functionalized Carbon Nanotubes. J. Am Chem Soc 131 (25): 9086-9093. 
Moon H., Lee S., Choi H., 2009. In Vivo Near-Infrared Mediated Tumor Destruction by Photothermal Effect of Carbon Nanotubes. ACS Nano 3 (11): 3707-3713.

Nelson D. J. and Kumar R., 2013. Characterizing Covalently Sidewall-Functionalized Single-Walled Carbon Nanotubes by Using ${ }^{1} \mathrm{H}$ NMR Spectroscopy. J. Phys. Chem. C 117: 14812-14823.

Nikfarjam M, Muralidharan V, Christophi C., 2005. Mechanisms of focal heat destruction of liver tumors. J. Surg. Res. 127: $208-223$.

Niu L., Meng L., Lu Q., 2013. Folate-Conjugated PEG on Single Walled Carbon Nanotubes for Targeting Delivery of Doxorubicin to Cancer Cells, Macromol Biosci 13 (6): $735-744$.

Novoa, L. V., 2012. Actividad de nanotubos de carbono acoplados a ácido fólico contra Leishmania panamensis después de irradiación con luz infrarroja cercana, Trabajo de Maestría en Ciencias básicas de la Escuela de Medicina, dirigida por Patricia Escobar R. UIS.

Pavitra Chakravarty, Radu Marches, Neil S. Zimmerman, Austin D.-E. Swafford, Pooja Bajaj, Inga H. Musselman, Paul Pantano, Rockford K. Draper, and Ellen S. Vitetta, 2008. Thermal ablation of tumor cells with antibodyfunctionalized single-walled carbon nanotubes, PNAS 105 (25): 8697-8702.

Robinson J., Welsher K., Tabakman S., Sherlock S., Wang h., Luong R., Dai H. , 2010. High Performance In Vivo Near-IR $(>1 \mu \mathrm{m})$ Imaging and Photothermal Cancer Therapy with Carbon Nanotubes. Nano Res. 3 (11): 779-793.
Tong R., Chiang H. H., and Kohane D. S., 2013. Photoswitchable nanoparticles for in vivo cancer chemotherapy. PNAS 110 (47): 19048-19053.

Vardharajula S., Ali SZ, Tiwari PM, Eroğlu E, Vig K, Dennis V.A, Singh S.R., 2012. Functionalized carbon nanotubes: biomedical applications. Int J Nanomedicine (7): 5361-74.

WANG H., ZHAO Y-L., and NIE G-J., 2013. Multifunctional nanoparticle systems for combined chemo-and photothermal cancer therapy. Front. Mater. Sci. 7 (2): 118-128.

Zhang Y L. X, Tang HM. D, Xie Q. T. L, Yao S, 2013. Biocompatible multi-walled carbon nanotube-chitosan-folic acid nanoparticle hybrids as GFP gene delivery materials. Colloids Surf B Biointerfaces 111C: 224-231.

Wadzanai, C., y Tebello, N., 2010. Characterization of aminefunctionalized single-walled carbon nanotube-low symmetry phthalocyanine conjugates. Carbon 48 (10): 2831-2838.

Zhao D., Alizadeh D., Zhang L., W. Liu, Farrukh O., Manuel E., Diamond D. J. and Badie B., 2011. Carbon Nanotubes Enhance $\mathrm{CpG}$ Uptake and Potentiate Antiglioma Immunity. Clin Cancer Res 17 (4): 771-782.

Zhou F.F., Wu S.N., Wu B.Y., Chen W.R., Xing D., 2011. Mitochondria-Targeting Single-Walled Carbon Nanotubes for Cancer Photothermal Therapy, Small 7 (19): 2727-2735.

Zhuang L., Corrine D., Weibo C., Lina H., Xiaoyuan C., and Hongjie D., 2008. Circulation and long-term fate of functionalized, biocompatible single-walled carbon nanotubes in mice probed by Raman spectroscopy. PNAS 105 (5): 1410-1415. 